\title{
PUERTOS COSTEROS DEL POSTCLÁSICO TEMPRANO EN EL NORTE DE YUCATÁN
}

\author{
ANTHONY P. ANDREws
}

\section{Introducción ${ }^{1}$}

Una síntesis de datos reunidos en recientes reconocimientos arqueológicos en las costas de la península de Yucatán aporta nueva evidencia en apoyo de la idea de que los grupos que se establecieron en Chichén Itzá en el siglo $\mathrm{X}$ tenían un pronunciado enfoque marítimo. Estos grupos venían de una tradición cultural que se basaba en la explotación de recursos marinos y costeros, y en el aprovechamiento de las rutas comerciales del litoral de la península.

Todavía más, los mismos datos sugieren que la base económica costera de estos grupos no solo facilitó su entrada en la península, sino que también contribuyó al mantenimiento del dominio político y cultural que ejerció Chichén Itzá sobre el norte de la península en los siglos XI y XII.

\section{Fondo histórico}

Gracias a la riqueza de las fuentes escritas y al carácter especial de los restos arqueológicos, el periodo Postclásico temprano fue una de las épocas más interesantes en la historia de las tierras bajas mayas. Pero los mismos datos históricos, mayormente de carácter legendario y un serio desequilibrio en el conocimiento de materiales

1 El autor agradece a J.M. Andrews, E.W. Andrews V, A. Benavides C., N. González C., E. Kurjack y F. Robles C. por los comentarios y revisiones edito. riales que brindaron en la preparación de este ensayo. También quisiera agradecer a J.W. Ball y J.D. Eaton, quienes generosamente me permitieron incluir aquí datos suyos aún no publicados. El contenido de este artículo es enteramente responsabilidad del autor. 
arqueológicos, han creado una visión de la época que a veces parece estar más apegada al mito que a la realidad.

Existe ahora una creciente coniente de opiniones compatibles que coinciden en fechar al periodo Postclásico temprano de Yucatán de 900/1000 a 1200 D.C. ${ }^{2}$ El periodo empieza gradualmente en el siglo $\mathrm{X}$ con el progresivo abandono, o semi-abandono de muchas de las comunidades que florecieron en el Clásico tardío y/o terminal (notablemente las afiliadas a la tradición Puuc), y con la concurrente entrada (o entradas) de grupos extranjeros al norte de Yucatán. Hacia 1000 D.C. estos grupos se encuentran bien establecidos en Chichén Itzá, ciudad de donde emanan las principales corrientes culturales que dominan a Yucatán en los siglos XI y XII. El periodo concluye con la caída de Chichén Itzá aproximadamente en 1200 D.C.

El principal evento de la época es la evolución de Chichén Itzá, y son de mucho interés las circunstancias que rodean a este suceso. En años anteriores se intentaba forzar la relación de dos eventos histórico-legendarios de Mesoamérica para explicar el origen de la capital itzá: la salida de Quetzalcóatl de Tula, y la llegada de Kukulcán a Yucatán. Aunque no se descarta la posible relación de estos dos sucesos, ahora son escenarios más complejos los que se proponen. Mayormente a base de su interpretación de fuentes históricas, J.E.S. Thompson (1970: 3-47) propuso dos migraciones a la península en el siglo $\mathrm{X}$, la primera por Cozumel y Pole (Xcaret) en 918 D.C., y la segunda por Chankanputún en 987 D.C. J.W. Ball (1974) ha propuesto un proceso más complicado, en el que intenta correlacionar datos arqueológicos y etnohistóricos: sugiere una primera entrada a fines del siglo VIII y una segunda, al igual que Thompson, en 987 D.C. Esta segunda entrada es la que comúnmente se asocia con la venida de Kukulcán. ${ }^{3}$

2 Este fechamiento es una reciente modificación de la cronología de E.W. Andrews IV (1965a), en la cual el Postclásico temprano lleva la apelación Floreciente Modificado. En una versión reciente de esta cronología, el período floreciente modificado comienza formalmente aprox. en 1000 D.C. (Ball y Andrews V, 1975). En el norte de la península, las siguientes fases cerámicas representan materiales del Postclásico temprano: fase Sotuta de Mayapán (Smith, 1971); fase Zipche de Dzibilchaltun (Ball y Andrews V, 1975); fase Vista Alegre de Quintana Roo (Sanders, 1960); y fase Guarnición, de las costas de Campeche y Yucatán (Ball, en prensa). El Período IV de la costa de Campeche también incluye materiales de esta época (Ruz Lhuillier, 1969). Para el fechamiento de los períodos cronológicos mencionados en este ensayo,
ver Cuadro 1 .

3 Aquí se han resumido en unas cuantas palabras dos secuencias de eventos bastante complejos. Para apreciar más a fondo los detalles y argumentos, refiero 
Postclásico Tardío o Decadente 1200 a 1540 D.C.

Postclásico Temprano

o Floreciente Modificado

$900 / 1000$ a 1200 D.C.

Clásico Terminal

o Floreciente Puro

$770 / 830$ a $900 / 1000$ D.C.

Clásico Tardío
o Temprano II
600 a $770 / 830$ D.C.

Clásico Temprano

o Temprano I 250 a 600 D.C.

Preclásico Tardío

o Formativo Tardío 300 A.C. a 250 D.C.

Cundro 1. Fechas aproximadas de los periodos cronológicos mencionados en este ensayo. Con la excepción del comienzo del Postclásico temprano, este cuadro sigue la cronología de Andrews V (en Ball y Andrews V, 1975).

Aunque aún no podemos definir con exactitud los detalles históricos que tuvieron como resultado la hegemonía de Chichén Itzá, la creciente compatibilidad de modelos históricos permite afirmar lo siguiente:

a) Grupos extranjeros, variablemente identificados como "toltecas", "maya chontal", "chontal", "chontal putun", "putun", "itzaes", o más cautelosamente, grupos étnicos no bien definidos, penetraron en la península y quedaron establecidos en Chichén Itzá a fines del siglo X.

b) Estos grupos penetraron por la costa trayendo consigo elementos de tradiciones culturales de la costa del golfo y del altiplano central.

c) Hacia 1000, desde su asiento en Chichén Itzá, estos grupos, ahora llamados "itzáes", ejercieron una fuerte influencia cultural sobre el norte de la península y es creencia común que esta influencia refleja un control político y económico de la región.

al lector a las obras citadas. Para análisis más minucioso de los datos arqueológicos, deben consultarse los trabajos de Kubler (1961) y Ruz Lhuillier (1964). 
Este resumen básico es lo que generalmente se acepta de los resultados de los estudios históricos e investigaciones arqueológicas, estas últimas realizadas sobre todo en Chichén Itzá. Irónicamente, son pocos los datos arqueológicos recabados fuera de Chichén Itzá que amplían este marco histórico (ver Ruz Lhuillier, 1964; Ball, 1974). Este es un serio problema de carencia de datos, puesto que en este caso nuestra comprensión de los eventos del Postclásico temprano en Yucatán está predominantemente basada en un solo sitio: Chichén Itzá.

Por otra parte, en años recientes se han obtenido nuevos datos de otros sitios, muchos de ellos aún no publicados, que amplían nuestros conocimientos de este periodo. Como se podrá apreciar a continuación, hay una notable diferencia entre la situación del interior de la península y de las costas.

\section{El interior de Yucatán en el Postclásico temprano}

Afuera de las cercanías de Chichén Itzá ${ }^{4}$ son relativamente pocos los restos culturales del Postclásico temprano. Hasta hace poco, la arquitectura monumental, escultura y arte mural que caracterizan al periodo no se habían reportado más que en la capital itzá. Recientemente se han identificado dos sitios más en el interior con restos arquitectónicos de la época -Dzibilchaltún y Culuba- pero éstos sólo presentan ocupaciones de poca importancia en esos sitios, donde la mayoría de la construcción es el periodo Clásico (Andrews IV, 1941; Andrews V, comunicación personal).

Por otra parte, hay varios sitios en donde se ha recuperado cerámica del Postclásico temprano, pero en cantidades relativamente menores en comparación con materiales de ocupaciones de otros periodos (algunos de estos sitios están incluidos en el plano de la Fig. 1). En contexto estratigráfico esta cerámica está aso-

4 Los resultados de investigaciones en la región de Chichén Itzá forman una extensa bibliografía en la cual resaltan los estudios de la Institución Carnegie de Washington, del Museo Peabody de la Universidad de Harvard, del Ins. tituto Nacional de Antropología e Historia de México, y del Middle American Research Institute de la Universidad de Tulane (Balankanche). Estudios más especializados, que analizan la naturaleza de elementos foráneos en Chichén Itzá y otros lugares, incluyen los de Kubler (1961) y Ruz Lhuillier (1969). Más recientemente los trabajos de Andrews IV (1965a), Thompson (1970) y Ball (1974) intentan aportar una perspectiva más amplia de lo que representó Chichén Itzá en el contexto de la península en el Postclásico temprano. 
ciada con materiales de la fase Sotuta de Mayapán (Smith, 1971) y de la fase Zipche de Dzibilchaltún (Andrews V, comunicación personal). Aparece en la superficie de los sitios Puuc, particularmente en Uxmal y Kabah (Smith, 1971; Saenz, 1972). Se ha encontrado también en los alrededores de Mérida (Shook, 1955; Garza T. de González, comunicación personal), en la superficie de Yaxcopoil y Culuba (Andrews V, comunicación personal) y en algunos sitios más en el interior de la península.

La cerámica del Postclásico temprano en estos sitios es bastante uniforme y los diversos tipos parecen estar dominados por inovaciones estilísticas desarrolladas en Chichén Itzá (Andrews IV, 1965: 320). Los tipos de manufactura local predominantes que se han definido son los comúnmente conocidos como "Pizarra Chichén", "Rojo Chichén" y sus variantes. Estos aparecen exclusivamente en el Postclásico temprano y son considerados como indicadores diagnósticos de ocupaciones de este periodo. Otros tipos de diagnósticos, menos comunes en el interior de la península son los importados, notablemente el naranja fino Silho (tipo "X") y el plomizo Tohil. Con excepción de Chichén Itzá, son raros los sitios en el interior en donde se encuentran estos tipos importados, la plomiza en particular.

En resumen, los datos ahora disponibles indican que el desplazamiento de materiales culturales asociados con Chichén Itzá en el interior de la península fue relativamente menor. Aunque futuras investigaciones indudablemente revelarán más sitios del interior con materiales de la época, los datos obtenidos hasta la fecha sugieren que la presencia de los itzáes en estos sitios fue bastante limitada. Es posible que estos restos reflejen la presencia mínima necesaria para garantizar el control de Chichén Itzá, es decir, de administradores y guarniciones itzáes (N. González C., comunicación personal).

Por otra parte, parece que hubo una gran concentración de actividad en la capital itzá. Como sugieren muchos autores, esta situación indica una centralización de poder político y recursos de una escala sin antecedentes en la historia de Yucatán. Algunos investigadores, incluso, proponen un imperio. Tal situación habrá requerido una fuerte base económica y una organización extremadamente eficiente para administrarlo. En parte, los itzáes habrán forjado su posición sobre una base de explotación de recursos humanos y productos agrícolas de los pueblos subyugados del nort

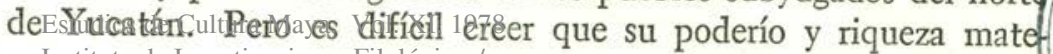


rial tenían una base tan limitada. Basta revisar nada más el inventario de materiales exóticos que Chichén Itzá importaba de tierras lejanas - del Altiplano central, de Guatemala y otros lugares de Centroamérica - para sospechar que los itzáes tenían acceso a una esfera económica mucho más amplia de la que proporcionaba el interior de Yucatán. En efecto, los restos arqueológicos de la época que se encuentran en las costas de la península sugieren que los itzáes estaban envueltos en una esfera económica de dimensiones mayores. ${ }^{5}$

\section{Las costas de Yucatán en el Postclásico temprano}

Hasta hace poco, eran escasos los materiales del Postclásico temprano que se conocían en las costas de la peninsula. Pero se han ido acumulando los datos de más de medio siglo de exploración, y junto con información obtenida en reconocimientos más recientes ya tenemos suficiente material para afirmar que la presencia de sitios con ocupaciones del Postclásico temprano es mucho más común de lo que anteriormente se suponía.

El litoral yucateco ha sido objeto de varios reconocimientos en los últimos 70 años. El primer estudio metódico fue el de S.K. Lothrop (1924) de la costa de Quintana Roo. Esta región siempre ha tenido un gran atractivo para investigadores y siguieron al estudio de Lothrop varios más: A. Escalona Ramos (1946), M.A. Fernández (1945), W.T. Sanders (1955, 1960), E.W. Andrews IV y A.P. Andrews (1975) y J.A. Sabloff y W.L. Rathje (1975). De las regiones costeras de la península, esta es la más estudiada y la mejor conocida.

La costa oeste, y en particular el sitio de Jaina, también han recibido bastante atención. Entre los estudios más destacados están los de E. Shook (1955), R. Piña Chan (1968), A. Ruz Lhuillier (1969), J.D. Eaton (en prensa) y J.W. Ball (en prensa). Por tin la costa norte es la que menos se ha estudiado, y hasta 1968 había sido totalmente ignorada. En ese año Eaton realizó un recorrido de la zona (en prensa; ver también Ball, en prensa). Un segundo reconocimiento se llevó a cabo en 1976, comg parte del proyecto del "Atlas Arqueológico del Estado de Yucatán" (A.P. Andrews, 1976b).

5 Este contraste, indudablemente exagerado, es el resultado del muestreo que ahora tenemos. Sin duda alguna, futuras excavaciones revelarán más sitios Estudioennle fulinteriónycon/ materiales del Postclásico temprano. 


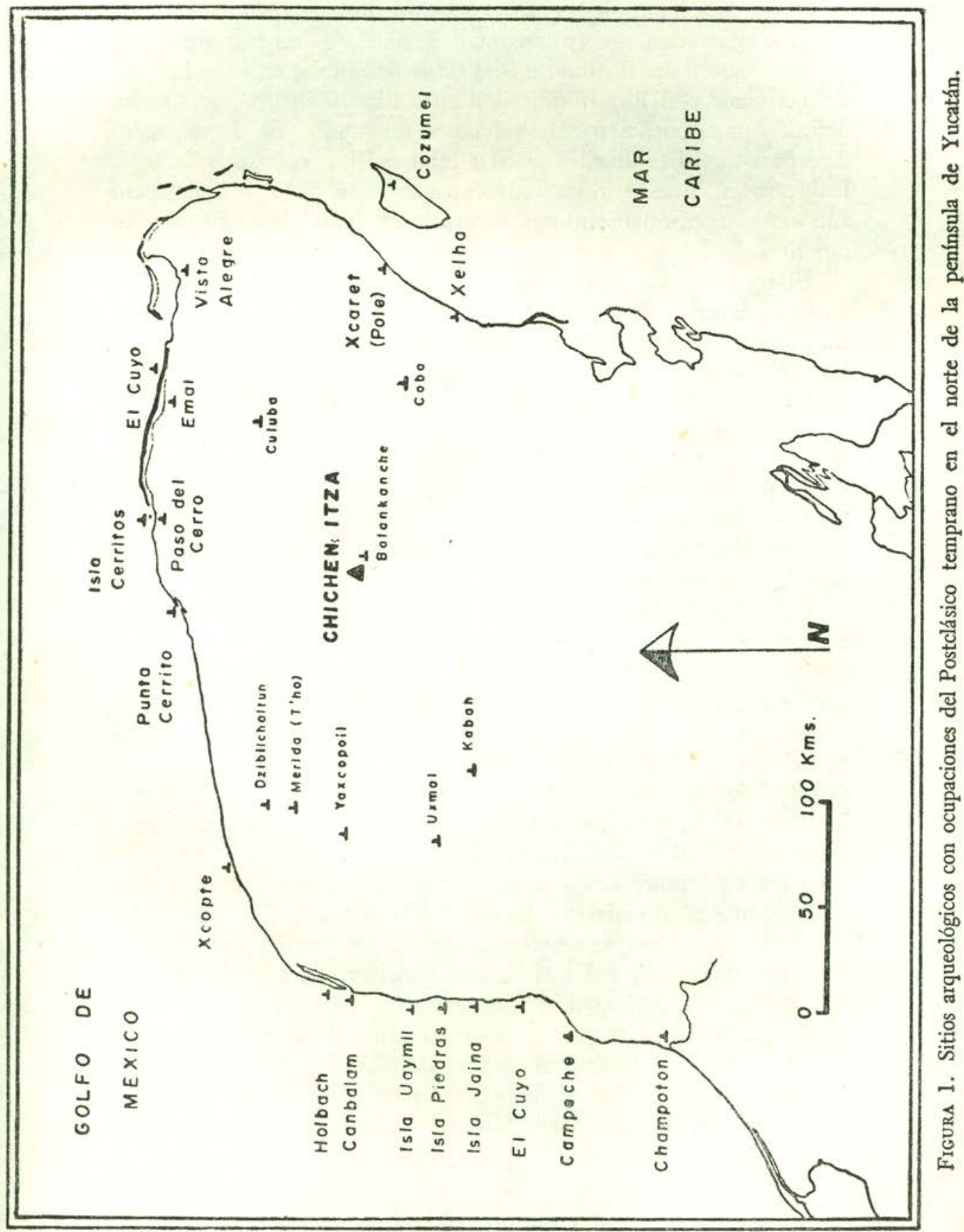

Estudios de Cultura Maya. Vol. XI, 1978

Instituto de Investigaciones Filológicas/

Centrõ de Estudios Mayas, UNAM 
Como resultado de estos reconocimientos son ahora más de 170 los sitios costeros (campamentos, aldeas y centros mayores) que se conocen en el litoral e islas de la península, entre la Laguna de Términos y el Río Hondo. De estos hay 18 en los cuales se ha definido una ocupación del Postclásico temprano (fig. 1; ver apéndice para una lista de sitios y citas bibliográficas correspondientes). Hay otros en que se sospechan ocupaciones en dicho periodo, pero aún no se confirman; futuras excavaciones indudablemente revelarán más.

El contraste en la cantidad de sitios del Postclásico temprano entre el interior y las costas es impresionante. En el interior se conocen más de un millar de sitios y apenas en unos cuantos se ha identificado una ocupación del periodo en cuestión, mientras que en las costas hay un alto porcentaje de localidades que lo reflejan. Aún más, en los sitios costeros está bien definida la ocupación por grandes cantidades de cerámica de superficie (particularmente en las costas norte y oeste). En colecciones de estos materiales resaltan los tipos importados, como la naranja fina Silho (tipo " $\mathrm{X}$ ") ${ }^{6}$ y la plomiza Tohil. Como se indicó antes, estos tipos son raros en sitios del interior fuera de Chichén Itzá.

Otro fuerte contraste con el interior es que en las costas se encuentran sitios donde la ocupación del Postclásico temprano es obviamente la predominante. Entre estos figuran El Cuyo (Camp.), Canbalam, Xcopte, Punta Cerrito, Isla Cerritos y Paso del Cerro.

Xcopte e Isla Cerritos tienen construcciones arquitectónicas que datan del Postclásico temprano. Son pequeños centros de carácter cívico-religioso e indudablemente representan los sitios más importantes del periodo en la costa norte. Aunque tienen algunos restos cerámicos de periodos anteriores, es evidente que su época de auge fue contemporánea a la de Chichén Itzá (Andrews IV, 1965b; Ball, en prensa). Todavía más, Ball y Eaton (1972; 774; Ball, 1947: 89) han propuesto que representan puertos comerciales de los itzá, íntimamente ligados a Chichén Itzá y mayormente dedicados a la explotación y comercio de la sal.

Isla Cerritos se encuentra a 600 metros de la costa norte de Yucatán, frente a la desembocadura del Río Lagartos. En la isla hay varias estructuras alrededor de una plaza y otras plataformas dispersas. En la superficie abunda, en cantidades no igualadas en

${ }_{6}^{6}$ Es probable que en los sitios de la costa norte de Campeche este tipo no represente una importación, puesto que varios autores concurren en que ésta fue su región de origen (Smith, 1958: 154; 1971: 21; Corson, 1976: 166; Ball, en prensa), pero ver Ruz Lhuillier (1969: 223-26). 
cualquier otro sitio costero, la cerámica del periodo, incluyendo una gran concentración de tipos importados. En el costado sur de la isla hay un dique artificial que forma un excelente puerto de abrigo para embarcaciones pequeñas. Además, quedan restos de un sacbé que comunicaba a la isla con tierra firme. Próximo al lugar donde llega a la costa el sacbé hay un canal (cuyo fondo está cubierto de cerámica prehispánica) que atraviesa aproximadamente 300 metros de manglar hasta llegar a una elevación de terreno en donde se encuentran una zona habitacional y varios montículos menores. Este es el sitio denominado "Paso del Cerro". Se encuentra junto a unas salinas con muros y diques prehispánicos, situación que sugiere fue una aldea salinera. De allí parte otro sacbé que cruza los pantanos detrás de la costa hasta llegar a tierra firme al costado sur de la ciénaga.

Isla Cerritos goza de una situación envidiable en cuanto a su posición en la costa. Aparte de Holbox, es el único sitio isleño en la costa norte; gracias a su localización pudo haber controlado no solo la ruta marítima costera, sino también el tráfico que salía del Río Lagartos (Eaton, en prensa). Por esta vía fluvial indudablemente salía mucha de la sal de las salinas de Emal, sitio que también sustentó una ocupación en el Postclásico temprano. Estas salinas, hoy conocidas como "Las Coloradas", son las más extensas de la región Maya. Esta situación, unida con el puerto de abrigo y la rica variedad de materiales importados hallados en la superficie de la isla, indican que Isla Cerritos fue importante puerto de comercio en el Postclásico temprano.

Vista en conjunto, la zona de Isla Cerritos representa un complejo portuario de carácter único en la costa, e indudablemente afiliada de la capital itzá. De los sitios costeros este es uno de los más cercanos a Chichén Itzá, encontrándose a $93 \mathrm{kms}$. al NNE de la capital, y es el más rico en restos de la época. En resumen, no creo que sea muy arriesgado proponer que este complejo costero fue el principal puerto de Chichén Itzá y su mayor base marítima en el litoral yucateco.

Los otros sitios costeros de la época son de menos importancia que Isla Cerritos, aunque parecen formar parte de un sistema integrado a los intereses de Chichén Itzá. De éstos, con la excepción de Isla Cerritos, Xcopte es la única con restos arquitectónicos del Postclásico temprano; pero el sitio es relativamente pequeño y es menor la cantidad y variedad de cerámica y artefactos que se encuentran allí (Eaton, en prensa). Por otra parte, El Cuyo (Camp.), Canbalam y Punta Cerrito son sitios bastante extensos, pero sin 
rasgos de construcciones de piedra; más bien son zonas de grandes concentraciones de cerámica, artefactos y restos ocupacionales de una población que vivía en casas de material perecedero.

Aparte de los sitios afiliados predominantemente al Postclásico temprano hay evidencia de ocupación contínua en comunidades establecidas en épocas anteriores. Entre éstas se incluyen Campeche, Champoton, Islas Jaina, Piedras y Uaymil, Holbach, Emal, El Cuyo (Yuc.), Vista Alegre, Xcaret (Pole), La Expedición (Cozumel) y Xelha. Con la posible excepción de Cozumel, en estos sitios no se ha observado evidencia de actividad arquitectónica durante el Postclásico temprano, pero las cantidades de cerámica sugieren ocupaciones relativamente fuertes.

A juzgar por los datos aquí resumidos, el litoral yucateco fue una zona de mucha actividad durante el Postclásico temprano. En particular, las costas norte y oeste (entre Champotón y Cabo Catoche) tienen restos de extensas zonas habitacionales. Como toda comunidad que se aprovecha de su medio ambiente, los sitios costeros yucatecos indudablemente representan aldeas y/o puertos en donde la gran mayoría de la población se dedicaba a la explotación de recursos marinos y costeros. Entre otras cosas se dedicaban a la pesca, a la recolección de moluscos, a la caza de tortuga, lagarto, manatí y varias especies de aves; en otras comunidades localizadas en zonas favorables se dedicaban a recolectar sal (Piña Chan, 1968; Andrews IV, 1969; Lange, 1971; Ball y Eaton, 1972; Eaton, 1976; Eaton, en prensa). Una tercera ocupación fue el comercio y es muy probable que todos los sitios aquí citados participaban en esa actividad. Las grandes cantidades de cerámica importada, entre otras cosas, apoyan esta sugerencia.

\section{Chichén Itzá, los puertos costeros y las salinas}

Es inevitable ver una relación entre los asentamientos costeros del Postclásico temprano y la ascendencia de Chichén Itzá. Aún más, la relación es de esperarse, pues los sitios costeros forman una parte lógica del escenario de eventos de la época.

Hasta hace poco el fenómeno de Chichén Itzá se explicaba como resultado de invasiones y/o migraciones de grupos que provenían directo del altiplano central. Como argumento se esgrimía la preponderancia de elementos "toltecas" que se han observado en Chichén Itzá. Más recientemente se proponen movimientos más graduales asociados a grupos intermedios de la costa del golfo, los llamados Chontal, Chontal-Putun o Putun. De ellos se ha dicho 
que están íntimamente ligados a la evolución y difusión de la cerámica naranja fina, con su origen en Tabasco y con su desplazamiento a lo largo del litoral yucateco (Thompson, 1970; Ball, 1974).

Esta reconstrucción de eventos pretende trazar el curso de las migraciones que llegaron a Chichén Itzá, pero no explica la causa de su migración, ni las circunstancias que permitieron que lograran su objetivo.

El desplazamiento de elementos foráneos en las costas yucatecas en el siglo $\mathrm{X}$ pone en marcha la serie de eventos históricos que culminan con el auge de los itzáes en el norte de la península. Pero los sitios costeros no fueron sencillamente puertos de paso para visitantes extranjeros; vistos en conjunto despliegan un patrón de distribución que sugiere que desempeñaron un importante papel en los procesos culturales de la península en el Postclásico temprano. Para apreciar su importancia es necesario ver más allá de un marco puramente histórico y tomar en cuenta factores geográficos, políticos y económicos.

Casi todos los sitios costeros en cuestión se localizan en posiciones estratégicas en el litoral y ello sugiere una asociación con rutas y actividades comerciales y militares. En particular, dos posiciones geográficas parecen haber atraido a los visitantes: 1) sitios isleños, como Jaina, Piedras, Uaymil, Cerritos y Cozumel, y 2) sitios localizados en las desembocaduras de ríos o estatuarios navegables, como Champotón (Río Champotón), Canbalam (Río Celestun), Punta Cerrito (Bocas de Dzilam), Isla Cerritos (Río Lagartos) y Vista Alegre (Río Turbio). Como se indicó arriba, Isla Cerritos está también localizado en la desembocadura de un río. Otros sitios, como Holbach, Xcopte, Paso del Cerro, Emal y El Cuyo (Yuc.) no están en posiciones tan estratégicas como los anteriores, pero se encuentran en zonas salineras, tema que se discutirá más adelante. También Holbach, Emal y El Cuyo (Yuc.) se encuentran a orillas de importantes vías fluviales (ríos Celestun y Lagartos). Por otra parte, Xcaret y Xelhá se encuentran junto a caletas que ofrecían excelentes puertos de abrigo naturales, frente a la isla Cozumel. Xcaret fue el principal puerto de embarque para la isla (Andrews IV y A.P. Andrews, 1975), y es probable que Xelhá haya sido el principal puerto de Cobá (Robles, comunicación personal). Al mismo tiempo que empiezan a aparecer elementos foráneos en estos sitios empiezan a abandonarse otros a lo largo del litoral (Ball y Eaton, 1972); no parece ser coincidencia que los sitios abandonados están en situaciones de poco valor estratégico. En resumidas cuentas, la distribución geográfica de los sitios costeros del Postclásico 
temprano sugiere una selección de posiciones claves a lo largo de las rutas marítimas de la península, que ofrecía obvias ventajas para operaciones comerciales o militares.

Es inevitable suponer que esta selección de asentamientos representó un esfuerzo consciente de grupos costeros aliados políticamente. Esta sugerencia se apoya en el desplazamiento de grupos que introdujeron la naranja fina (en este caso el Balancán o tipo "Z") a la península en el siglo IX y principios del X. Esta cerámica se halla en varios de los sitios aquí citados, en particular en los de la costa de Campeche. Como sugieren varios autores, esta introducción estimuló la manufactura, en la costa norte de Campeche, del naranjo fino Silho (tipo " $\mathrm{X}$ "), que después aparece en otros sitios costeros asociado con materiales de manufactura local del norte de la península (Ball, 1974; en prensa). El hecho de que los puertos costeros llegaron a compartir una tradición cerámica íntimamente ligada a Chichén Itzá indica una consolidación de unidad política y por consiguiente, económica y militar, con base en la capital itzá.

Finalmente, falta considerar la estructura comercial del Postclásico temprano para poner en perspectiva a los factores arriba descritos. A juzgar por los datos ahora disponibles, el norte de $\mathrm{Yu}$ catán ya participaba en un fuerte comercio de larga distancia desde el periodo Clásico temprano, y posiblemente, desde el formativo tardío. A las tierras del norte llegaba una gran cantidad de materiales importados de alto valor: obsidiana, jade, basalto, sílex fino, cerámica polícroma, naranja fina y otros productos que reflejan un fuerte comercio exterior. En cambio, el norte de Yucatán ofrecía un inventario de artículos de mucho menos valor: miel, productos de algodón, esclavos, copal y otros similares (Cardós de Méndez, 1959; Thompson, 1970). Es difícil suponer que hubiesen podido pagar por los materiales importados con estos artículos.

El principal recurso fuerte para el comercio de larga distancia que poseía Yucatán era la sal. A lo largo de la costa norte, de Celestun a $\mathrm{El}$ Cuyo, yacen las salinas más extensas de la región maya. Estas salinas tienen una producción potencial capaz de satisfacer las necesidades de consumo de todas las tierras bajas mayas. Es más, en el siglo XVI surtían a las costas del golfo, hasta Tamaulipas y a las costas del Caribe hasta Honduras. Después de la Conquista esta sal también se enviaba al Altiplano central y a Cuba (A.P. Andrews, 1974). Las salinas yucatecas han sido explotadas desde la época formativa (Eaton, en prensa) y es probable que formaron una importante base económica para el desa- 
rrollo de las grandes comunidades del norte de Yucatán durante el período Clásico (Andrews IV, 1968: 36). Por ejemplo, es probable que las grandes cantidades de cerámica polícroma que fueron importadas del Petén al norte de Yucatán fueron adquiridas mediante un intercambio con la sal (Andrews IV, 1969: 60).

Siendo la sal el principal recurso de intercambio para el comercio de larga distancia, es lógico suponer que las comunidades que controlaban las salinas tenían una fuerte influencia sobre el comercio de las rutas costeras de la península. Por consiguiente, no es sorprendente encontrar que varios de los puertos del Postclásico temprano estén localizadas en zonas salineras de gran importancia. Holbach, Xcopte, Emal y El Cuyo (Yuc.) se encuentran en medio de las salinas más extensas de la costa norte, mientras que Punta Cerrito y Paso del Cerro yacen junto a otras salinas menores. Las características internas de estos sitios parecen indicar que fueron centros administrativos y/o aldeas de las salinas (A.P. Andrews $1976 b$; Eaton, en prensa).

En un breve estudio reciente, Ball y Eaton (1972) proponen que las ocupaciones del Postclásico temprano en Xcopte y Emal indican una dominación itzá de las salinas adjuntas. Es más, observan un aumento de ocupaciones costeras durante este período y esto lo relacionan con un incremento en la explotación salinera por parte de los itzáes. Datos más recientes apoyan estas sugerencias, puesto que se han localizado varios sitios salineros adicionales. del período: Holbach, Punta Cerrito, Paso del Cerro y El Cuyo. (A.P. Andrews, 1976b).

\section{Conclusiones}

Como han propuesto varios autores, los eventos del Postclásico temprano en el norte de Yucatán están íntimamente relacionados con acontecimientos costeros. Los datos y argumentos aquí reunidos se enfocan sobre esta relación y en particular sobre la dimensión económica. A base de estos materiales se puede ofrecer una interpretación más amplia de los hechos, sin intentar reconstruir o aclarar detalles históricos, ni contradecir los escenarios que se han propuesto hasta la fecha; más bien, la interpretación los acepta en forma general e intenta incorporar factores económicos.

Empezando a fines del siglo IX y en el transcurso del siglo $\mathrm{X}$ grupos extranjeros de un carácter decididamente mercantil (Thompson, 1970; Sabloff y Rathje, 1975b), atraidos por el rico comercio 
costero y los recursos salineros, ${ }^{7}$ se desplazaron por las costas yucatecas, estableciendo una red de puertos costeros a lo largo del litoral.

A través de esta serie de maniobras los invasores mermaron el comercio costero (y su principal recurso, las salinas) de las comunidades del Clásico terminal del interior del norte de Yucatán. Ahora se cree que estas comunidades sufrían de una presión demográfica muy fuerte y al mismo tiempo de recursos más limitados; más que nunca en su historia dependían en gran parte de su acceso a recursos marinos, el comercio costero y las salinas para sobrevivir (Kurjack y Andrews V, 1976). La intrusión de los grupos foráneos en las costas acabó con estas importantes fuentes de ingresos y le proporcionó el "coup de grace" a la ya inestable economía del interior.

Al mismo tiempo que se debilitaba la situación económica, y por consiguiente la política, en el interior, los grupos costeros entraron y se establecieron en Chichén Itzá. Aprovechándose de la desorganización, fueron consolidando su poder político en la península. La segunda entrada de grupos posiblemente más aguerridos $\mathrm{y}$ mejor organizados, a fines del siglo $\mathrm{X}$, puso fin a la etapa de conquista, y quedó establecido Chichén Itzá como capital política del norte de Yucatán.

El mantenimiento, por más de dos siglos, de dominio político sobre el norte de la península no se efectuó solamente con la fuerza de las armas. Como se observó anteriormente, ese poderío requirió una base económica y es evidente que el interior no lo podía pro. porcionar. Más allá de explotar los recursos humanos y la producción agrícola, era poco el interés de los itzáes en las comunidades del interior, ahora devastadas por los eventos del siglo anterior. La marcada escasez de cerámica y arquitectura asociada estilísticamente con Chichén Itzá es una buena indicación de ese desinterés. Como se propuso antes, es posible que los materiales que se han encontrado sean los restos de pequeños grupos de residentes foráneos que velaban por los intereses de la capital itzá.

En efecto, la principal base económica se encontraba en las costas, y los itzáes invirtieron mucha energía en consolidar su situación allí. La construcción de centros administrativos en las salinas, el establecimiento de complejos portuarios como el de Isla Cerritos (posible puerto de Chichén Itzá) y la localización de

7 La idea de que factores económicos formaron parte de la atracción que ofrecía Yucatán a grupos extranjeros no es nada nueva. Hace medio siglo, en 1929, Mendizábal (1946: 330) propuso que las salinas fueron el principal objetivo de los grupos que migraron hacia Yucatán. 
puertos en posiciones claves para el comercio y en situaciones estratégicas para defensa (como islas) fueron el resultado de esta consolidación. Económicamente, el control costero les proporcionó acceso a dos esferas comerciales: 1) al comercio interno, ya que podían controlar la distribución de recursos marinos y sal a los sitios del interior, y 2) el comercio de larga distancia, en donde podían exportar la sal y otros productos del interior a tierras distantes y a cambio recibir los materiales que producían estas. Naturalmente, estos materiales (obsidiana, jade, metales, cerámica plomiza, etcétera) se concentraban en Chichén Itzá.

En fin, Chichén Itzá no hubiese llegado a ser lo que fue sin haber sido también el resultado de un fenómeno económico de dimensiones mayores. A este fenómeno se debe el que los itzáes pudieran concentrar el poderío político y económico en una sola ciudad. Y es extremadamente dudoso que hubiesen logrado ésto sin tener un control absoluto de las costas, los recursos marinos, las rutas comerciales y su principal recurso, las salinas.

Las circunstancias que rodean la caída de Chichén Itzá hacia 1200 D.C. añaden apoyo a la interpretación que aquí se propone. Según fuentes históricas, la capital itzá fue arrasada por grupos mayas del interior y este evento fue seguido por el establecimiento de un nuevo orden político que se formaliza con la fundación de Mayapán hacia mediados del siglo XIII. Con el surgimiento de Mayapán ocurre un renacimiento de actividad a través de la península. Aparecen nuevas construcciones en varios sitios del interior y hay un florecimiento cultural de dimensiones mayores en la costa oriental de la península. Pero al mismo tiempo son abandonados la mayoría de los sitios costeros del litoral norte y oeste. Hasta la fecha sólo se han hallado materiales del Postclásico tardío en tres de los sitios de las costas norte y oeste indicados en el plano de la figura 1: en Champotón, Emal y Vista Alegre. Esta situación no deja duda alguna de que el orden económico costero que habían forjado los itzáes se desplomó junto con la caída de Chichén Itzá. La actividad costera siguió (Mayapán y otros sitios continuaron 4 explotando los recursos marinos y las salinas), aunque la mayor parte de ella se desplazó a las costas del Caribe, posiblemente hacia nuevas rutas de intercambio. Pero el sistema económico de las costas norte y oeste pasó a la historia junto con la capital itzá. 


\section{APENDICE: REFERENCIAS BIBLIOGRÁFICAS DE SITIOS COSTEROS DEL LITORAL YUCATECO DEL PERIODO POSTCLÁSICO TEMPRANO (En orden alfabético)}

Campeche, Camp.:

Canbalam, Camp.:

Champotón, Camp.:

El Cuyo, Camp:

El Cuyo, Yuc.:

Emal, Yuc.:

Holbach, Camp.:

I. Cerritos, Yuc.:

I. Cozumel, Q. Roo:

I. Jaina, Camp.:

I. Piedras, Camp.:

I. Uaymil, Camp.:

Paso del Cerro, Yuc.:

Punta Cerrito, Yuc.:

Vista Alegre, Q. Roo:

Xcaret, Q. Roo:

Xcopte, Yuc.:

Xelha, Q. Roo:
Ruz Lhuillier, 1969; Ball, en prensa.

Shook, 1955; Ball, en prensa.

Ruz Lhuillier, 1969; Ball y Eaton, 1972; Eaton, en prensa; Ball, en prensa.

A.P. Andrews, $1976 a$.

Ball y Eaton, 1972; A.P. Andrews, 1976b; Eaton, en prensa; Ball, en prensa.

Ball y Eaton, 1972; Eaton, en prensa; Ball, en prensa.

A.P. Andrews, $1976 a$.

Andrews IV, 1965b; Ball y Eaton, 1972; A.P. Andrews, 1976 $b$; Eaton, en prensa, Ball, en prensa.

(sitio La Expedición) Sabloff y Rathje, 1975 .

Ver Piña Chan (1968), Corson (1976) y A.P. Andrews (1976a) para bibliografías del sitio.

Shook, 1955; Ball y Eaton, 1972; Eaton, en prensa; Ball, en prensa.

Shook, 1955; Ball y Eaton, 1972; Eaton, en prensa; Ball, en prensa.

A.P. Andrews, $1976 b$.

A.P. Andrews, $1976 b$.

Sanders, 1955, 1960.

Andrews IV y A.P. Andrews, 1975.

Ball y Eaton, 1972; Ball, 1974; Eaton, en prensa; Ball, en prensa.

Lothrop, 1924; Navarrete, 1974.

Nota: esta lista no intenta aportar bibliografías completas de cada sitio. Solo incluye obras que contienen las mejores descripciones y datos cronológicos de los sitios. 


\section{BIBLIOGRAFIA}

ANDREws, A.P.

1974 (Ms) Salt and the Maya. Mecanuscrito.

1976a Historia de investigaciones, localización, índice y bibliografía de sitios prehispánicos en la costa norte de Campeche, México. Reporte inédito, Archivos del Centro Regional del Sureste, I.N.A.H., Mérida.

$1976 b$ Indice y bibliografía de sitios prehispánicos de la costa del Estado de Yucatán, México. Reporte preparado para el proyecto "Atlas Arqueológico del Estado de Yucatán". Reporte inédito, Archivos del Centro Regional del Sureste, I.N.A.H., Mérida.

ANDrews IV, E.W.

1943 "The Ruins of Culuba, Northeastern Yucatan." Carnegie Institution of Washington, Notes on Middle American Archaeology and Ethnology, Vol. I, No. 3: 11-14.

1965 a "Archaeology and Prehistory in the Northern Maya Lowlands." Handbook of Middle American Indians, 2: 288. 330.

1965 b "Progress Report on the 1960-1964 Field Seasons, National Geographic Society - Tulane University Dzibilchaltun Program." Tulane University, Middle American Research Institute, Publ. 31: 23-67. New Orleans.

1968 "Dzibilchaltun, a northern Maya Metropolis." Archaeology, 21: 36-47.

1969 "The Archaeological Use and Distribution of Mollusca in the Maya Lowlands." Tulane University, Middle Amer. ican Research Institute, Publ. 34. New Orleans.

ANDrews IV, E.W. y A.P. ANDrews

1975 "A Preliminary Study of the Ruins of Xcaret, Quintana Roo, Mexico. With notes on other archaeological remains on the east coast of the Yucatan peninsula." Tulane University, Middle American Research Institute, Publ. 40. New Orleans.

BALL, J.W.

1974 "A Coordinate Approach to Northern Maya Prehistory: 700 - 1200 A.D. American Antiquity, 39 (\# 1): 85-93.

En prensa Archaeological Pottery of the Yucatan-Campeche Coast. Tulane University, Middle American Research Institute. New Orleans.

BALL, J.W. y J.D. Eaton

1972 "Marine Resources and the Prehistoric Lowland Maya: A Comment. American Anthropologist, 74 (\# 3): $772-76$. 
BALL, J.W. y E.W. ANDrews V.

1975 "The Polychrome Pottery of Dzibilchaltun, Mexico: Typology and Archaeological Context." Tulane University, Middle American Research Institute, Publ. 31: 227-44. New Orleans.

Cardós de Méndez, A.

1959 "El Comercio de los Mayas Antiguos." Acta Antropoló.

Corson, C. gica, Epoca 2, Vol. II, No. 1, E.N.A.H., México.

1976

"Maya Anthropomorphic Figurines from Jaina Island, Campeche." Ballena Press Studies in Mesoamerican Art Archaeology and Ethnohistory, No. 1. Ramona, California.

EAton, J.D.

1976 "Ancient Fishing Technology on the Gulf Coast of Yucatan, Mexico." Bulletin of the Texas Archaeological Society, 47: 231-43. Austin.

En prensa Archaeological Survey of the North and West Coasts of the Yucatan Peninsula, Mexico. Tulane University, Mid. dle American Research Institute. New Orleans.

Escalona Ramos, A.

1946 "Algunas ruinas prehispánicas en Quintana Roo." Boletín de la Sociedad Mexicana de Geografía y Estadística, 61

FERNÁNDEZ, M.A. (\# 3): 513-628. México.

1945 "Exploraciones arqueológicas en la Isla Cozumel." Anales del I.N.A.H., I: 107-120. México.

Kubler, G.

1961 "Chichén Itzá y Tula". Estudios de Cultura Maya, I: 47-79. U.N.A.M., México.

KurJack, E.B. y E.W. ANDrews IV

1976 "Early Boundary Maintenance in Northwest Yucatan, Me-

LANGE, F.W. xico." American Antiquity, 41 (\# 3): 318-25.

1971 "Marine Resources: A Viable Subsistence Alternative for the Prehistoric Lowland Maya." American Anthropologist,

Lothrop, S.K. 73 (\# 3): 619-39.

1924 "Tulum. An Archaeological Study of the East Coast of Yucatan." Carnegie Institution of Washington, Publ. 335.

MENDIZÁBAL, M.O. DE

1946 "Influencia de la sal en la distribución geográfica de los grupos indígenas de México." En Obras Completas, Vol.

Navarrete, C. II: 181-340. México [2a. edición; orig. 1929].

1974 "Material cerámico de la cueva de Xelha, Quintana Roo." U.N.A.M., Notas Antropológicas, I (Nota 8): 53-57. Mé-

Piña Chan, R. xico.

1968 Jaina. La Casa en el Agua. I.N.A.H., México. 
RUz LHUILLIER, A.

1964 "Influencias Mexicanas sobre los Mayas." En Desarrollo Cultural de los Mayas (E.Z. Vogt y A. Ruz Lhuillier, eds.): 195-227. Centro de Estudios Mayas, U.N.A.M., México.

1969 "La Costa de Campeche en tiempos prehispánicos." I.N.A.H., Serie de Investigaciones, No. 18, México.

Sabloff, J. A. y W.L. Rathje (eds.)

1975a "A Study of Changing Pre-Colombian Commercial Systems. The 1972-1973 Seasons at Cozumel, Mexico." Harvard University, Monographs of the Peabody Mu seum, No. 3. Cambridge, Mass.

$1975 \mathrm{~b}$ "The Rise of a Maya Merchant Class. Scientific American, 233 (\# 4): 72-82.

SAENZ, C.A.

1972 "Exploraciones y restauraciones en Uxmal (1970-1971)." Boletín del I.N.A.H., Época II, No. 2: 31-40.

SANDERS, W.T.

1955 "An Archaeological Reconnaissance of Northern Quintana Roo." Carnegie Institution of Washington, Current Reports, 2 (\# 24): 179-219.

1960 "Prehistoric Ceramics and Settlement Patterns in Quintana Roo, Mexico." Carnegie Institution of Washington, Publ. 606 (Contrib. 60).

SHoor, E. M.

1955 "Yucatan and Chiapas." Carnegie Institution of Wash ington, Yearbook, No. 54: 289-95.

SMITH, R.E.

1958 "The Place of Fine Orange Pottery in Mesoamerican Archaeology." American Antiquity, 24 (\# 2): 151-60.

1971 "The Pottery of Mayapan." Harvard University, Papers THOMPson, J.E.S. of the Peabody Museum, Vol. 66. Cambridge, Mass.

1970 Maya History and Religion. Norman, Oklahoma. 